\title{
Integração de sistemas para a Governança Eletrônica na Assembléia Legislativa do Estado de Santa Catarina
}

\author{
Dayna Maria Bortoluzzi ${ }^{1}$, Nilson Ribeiro Modro ${ }^{2}$, Fernanda Oviedo Bizarro ${ }^{3}$ \\ ${ }^{1}$ Instituto Gene - Blumenau, SC - Brasil. \\ http://www.institutogene.org.br/ \\ ${ }^{2}$ Departamento de Sistemas de Informação \\ Universidade do Estado de Santa Catarina (UDESC) - São Bento do Sul, SC - Brasil. \\ ${ }^{3}$ Departamento de Ciências da Computação \\ Universidade do Sul de Santa Catarina (UNISUL) - Florianópolis, SC - Brasil. \\ dayna.maria@gmail.com, nilsonmodro@sbs.udesc.br, oviedo@unisul.br
}

\begin{abstract}
Resumo. Apresenta-se a solução tecnológica adotada para a integração de sistemas no âmbito do projeto de Governança Eletrônica da Assembléia Legislativa do Estado de Santa Catarina (ALESC), cujo objetivo é garantir maior transparência e melhor atendimento ao cidadão catarinense, a partir da gestão integrada das informações. A Governança Eletrônica dos sistemas integrados permitirá o gerenciamento eletrônico dos processos e documentos da ALESC, por meio da utilização de ferramentas e softwares que possibilitarão mecanismos de busca eficaz, bem como o controle de processos internos existentes na casa.
\end{abstract}

\section{Introdução}

Em 2005, durante a realização de um diagnóstico situacional, com ênfase as áreas Parlamentar e Administrativa, da casa na Assembléia Legislativa do Estado de Santa Catarina (ALESC) foi identificada a necessidade de elaborar um Projeto de Governança Eletrônica (GE) na ALESC. Um projeto de GE que, a partir de um modelo de gestão inovador, permita agilidade, melhor controle, transparência e eficácia na administração pública e nas respostas dos processos que envolvam a participação de gestores do poder público e parlamentares [BORRAS, 2004; BONAVIDES \& ANDRADE, 2004; RODHES, 2000; GRAU, 1997].

Analisando a ALESC, seus sistemas legados, a quantidade de papel utilizada e o fluxo dos processos existentes, sugeriu-se a implantação de um sistema integrador e que contemple a conversão de documentos físicos para um formato digital, abrangendo o fluxo dos processos envolvidos e a conseqüente redução dos custos operacionais do processo administrativo, bem como, a produção de informações para os níveis decisórios.

O objetivo de tal solução é integrar os sistemas do poder legislativo do estado de Santa Catarina a fim de permitir a realização de consultas, através da Internet, sobre o andamento dos processos públicos e a visualização de seu conteúdo. Parte-se da premissa que a partir de um meio de acesso rápido a informação o cidadão catarinense acompanhe as atividades dos parlamentares, cobrando a atuação prometida em época de 
campanha eleitoral. Também se pretende formar uma rede documental histórica que sirva de consulta para estudantes e profissionais da área de advocacia, e futuramente, a integração com sistemas de outros poderes facilitando à execução das atividades dos servidores públicos [LAPORT et al, 2002; REZENDE et al, 2003].

Nesse sentido, para a efetiva implantação da solução proposta de Governança Eletrônica, foi necessária a integração das plataformas de tecnologia da informação, tais como, base de dados, sistemas operacionais, linguagens de programação e aplicativos, além de utilizar tecnologias de gestão eletrônica de documentos, recuperação de informações com inteligência artificial e visualização das informações.

Atualmente, a implantação do projeto na ALESC vem sendo gerenciada pela coordenadoria de informática, sendo que a integração do legado de sistemas existentes com as ferramentas adquiridas recentemente é feita através de uma ferramenta de integração, cuja finalidade é disponibilizar os dados coorporativos para todas as aplicações, agregando valor às informações hoje existentes de forma a contribuir para o aperfeiçoamento do planejamento estratégico.

Este artigo apresenta de modo descritivo, o funcionamento do fluxo de sistemas da ALESC, a necessidade de organização da informação, as tecnologias utilizadas e as vantagens esperadas com a implantação do projeto de Governança Eletrônica.

\section{A Assembléia Legislativa de SC}

Atualmente, a Assembléia Legislativa de Santa Catarina é formada por quarenta (40) deputados eleitos como representantes do povo catarinense, para um período de quatro (4) anos, tendo como missão institucional exercer o Poder Legislativo no âmbito do Estado. Suas principais tarefas são: fazer leis, regulando parte significativa da vida social do povo catarinense, e fiscalizar os atos do Governo Estadual [ALESC, 2006].

A função básica do poder Legislativo é a criação do direito positivo infraconstitucional, elaborando, revogando, alterando, emendando as leis e desempenhando a função do poder constituinte de segundo grau (através da autorização constitucional), além de outras funções expressamente estabelecidas pela Constituição.

Outras funções secundárias também são executadas pelo poder Legislativo, tais como, a função administrativa e a função julgadora. A função administrativa fixa a remuneração de seus membros observando sempre o Texto Constitucional, a disposição quanto à organização e outras incumbências administrativas. A função julgadora autoriza a instauração de processo contra o chefe do poder executivo correspondente, e os seus escolhidos para cada setor do poder que representa, neste caso específico os secretários de estado, podendo até mesmo processá-los e julgá-los.

O Acompanhamento do Processo Legislativo é feito através em várias etapas que vão desde a fase inicial - protocolo de entrada - até a publicação da lei, ou arquivamento de qualquer processo do Poder Legislativo. A Figura 1 apresenta o fluxo do processo parlamentar e em seguida é apresentada a descrição resumida das atividades realizadas em cada uma das etapas. 


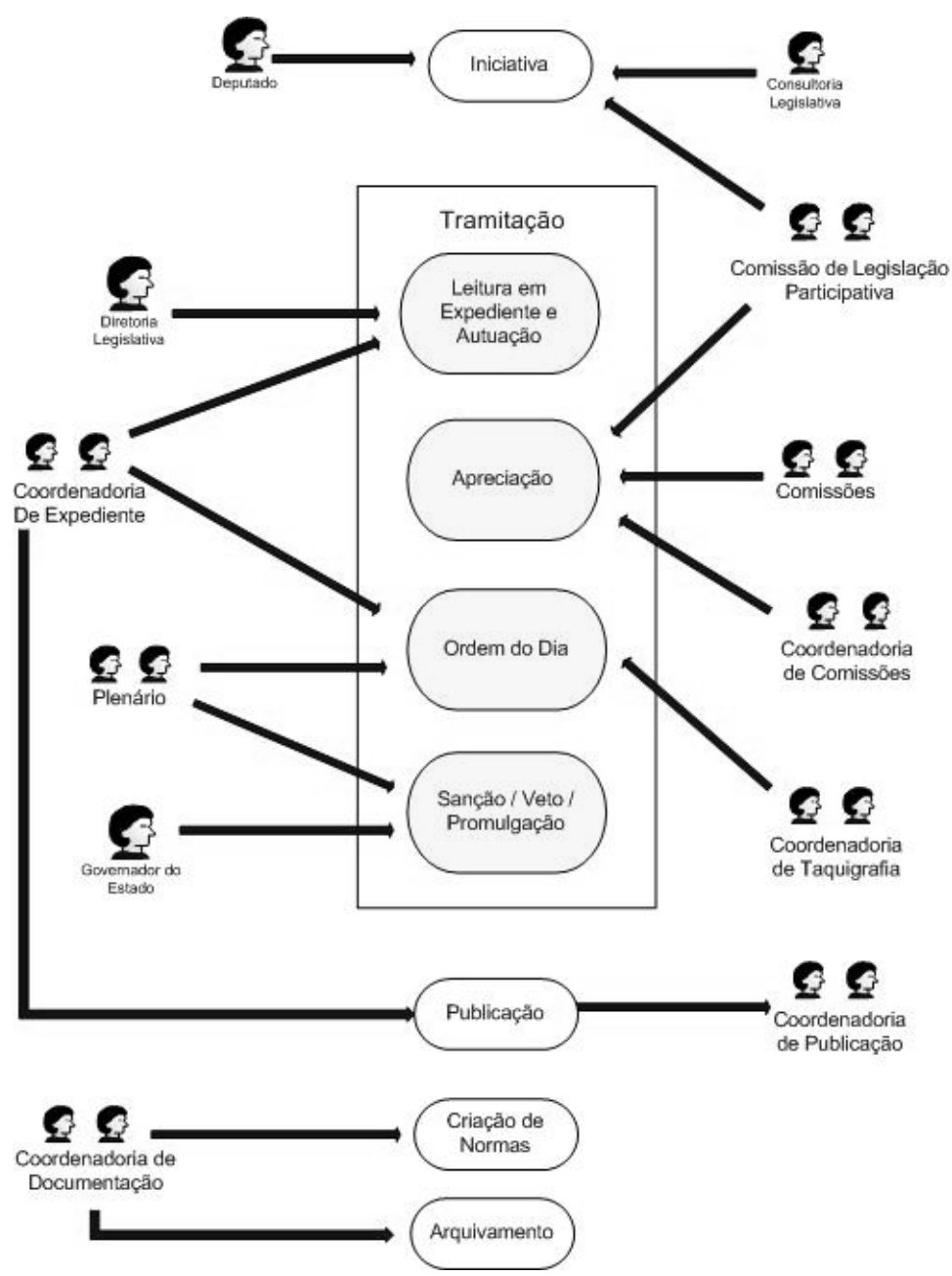

Figura 1 - Acompanhamento do Processo Parlamentar

a) Iniciativa: É o processo através do qual os deputados, com ou sem o auxílio da Consultoria Legislativa, criam projetos (projeto de lei, medida provisória, etc.) propondo alguma matéria, que pode vir a ser discutida e votada em plenário.

b) Leitura em Expediente e Autuação: Após a iniciativa, a sugestão legislativa deve passar pela leitura em Expediente, que é realizada durante o "Pequeno Expediente" da Sessão Plenária. Pode ser descrito como o ato da leitura da ementa do projeto e seu autor, para que os deputados tomem conhecimento de sua existência.

c) Apreciação: Após ter sido autuado, o processo legislativo é encaminhado pela Coordenadoria de Expediente à Coordenadoria das Comissões para que a matéria tenha sua constitucionalidade e seu mérito apreciados pelas comissões de direito.

d) Ordem do Dia: Após ter sido apreciada pelas comissões temáticas, a proposição volta para a Coordenadoria de Expediente, para que entre na Pauta para a Ordem do Dia.

e) Sanção / Veto / Promulgação: Após ter sua redação final aprovada em plenário, a proposição (no caso de projeto de lei e projeto de lei complementar) é enviada 
ao governador do estado para ser sancionada. O governador pode sancionar a lei ou vetá-la.

f) Publicação: As matérias são publicadas em pelo menos em duas situações: quando são propostas e quando se transformam em norma jurídica. Em ambos os casos a publicação é feita no Diário da Assembléia.

g) Criação de Normas: O processo de criação de leis consta na transcrição do texto do projeto para a lei e sua devida numeração. Quando um projeto de lei é sancionado pelo governador ele se transforma em uma Lei Sancionada. Quando um projeto de lei é vetado, mas seu veto não é mantido em plenário, ele se transforma em uma Lei Promulgada.

h) Arquivamento: Uma proposição após ter sua tramitação encerrada, seja porque virou norma ou porque foi rejeitada, é enviada para a Coordenadoria de Documentação para que seja feito seu arquivamento.

Atualmente, onze (11) sistemas são utilizados no acompanhamento do processo parlamentar, descrito na Figura 1, sendo que considerando as áreas administrativa e parlamentar a ALESC possui hoje cerca de trinta (30) sistemas, servindo às diversas necessidades da instituição. Este conjunto de sistemas vem evoluindo ao longo dos anos através de tecnologias, mas conservam uma necessária relação de interdependência.

O ambiente tecnológico da ALESC é composto basicamente de sistemas desenvolvidos ou, em desenvolvimento, nas linguagens Delphi e PHP, utilizando o MySql como banco de dados. Todos os sistemas desenvolvidos sobre estas plataformas estão hospedados num único servidor Linux. Além disto, a ALESC também possui sistemas legados desenvolvidos em Mumps que visam atender as áreas administrativas e financeiras.

A necessidade de integração, controle e gerenciamento de todos os processos realizados na ALESC, desde seu início até a emissão e arquivamento dos processos, é essencial num âmbito de gestão e segurança da informação.

Implementar um Projeto de Governança Eletrônica na ALESC auxilia no controle da tramitação dos documentos permitindo sua rápida localização e acesso, maior agilidade e segurança na recuperação da informação e a formação de um patrimônio documental da instituição. Associado a esta base de documentos faz-se essencial a utilização de instrumentos de pesquisa que permitam a agilidade na obtenção da informação. Quanto maior for à base de documentos melhor devem ser os algoritmos de Inteligência Artificial a fim de permitir o acesso rápido à informação.

Além de introduzir a ALESC à modernidade naquilo que diz respeito à administração da coisa pública, o projeto permite que os funcionários da Casa e todos os cidadãos catarinenses tenham acesso, com qualidade e transparência, a tudo aquilo que acontece dentro dela, acarretando inclusive uma evidente redução de custos operacionais.

\section{A Solução Tecnológica}

A solução tecnológica utilizada no Projeto de Governança Eletrônica da ALESC está baseada nas tecnologias correlatas de EAI - Integração de plataformas de tecnologia da Informação (Enterprise Application Integration), IA - Inteligência Artificial (AI - 
Artificial Intelligence) e GED - Gerenciamento Eletrônico de Documentos. Também consta no projeto a adoção de modernas metodologias, tecnologias e infra-estruturas para o gerenciamento físico e armazenamento dos documentos e informações, de forma segura e com localização objetiva e rápida (Figura 2).

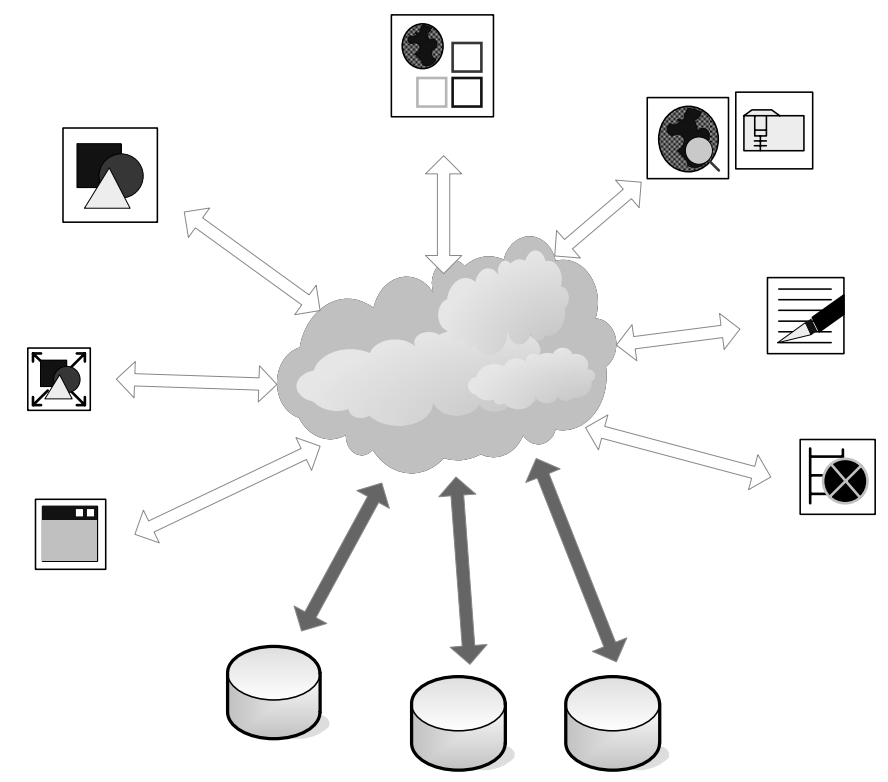

Figura 2 - Solução Tecnológica

\subsection{Integração}

A integração está sendo feita através da utilização da ferramenta Ensemble (Enterprise

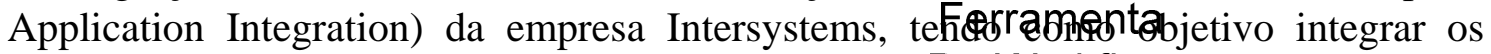
sistemas e permitir o acompanhamento e execuça Workfoutessos (workflow) [INTERSYSTEMS, 2006]. Neste sentido, o Quadro 1 apresenta as principais vantagens da utilização de uma ferramenta de Integração na ALESC.

Quadro 1 Vantagens da integração de Sistemas na ALESC

Melhorar o gerenciamento das informações, reduzir replicações de bases de dados, eliminar redundância de informações, garantịr integridade das bases coorporativas

Possibilitar a integração de diferentes plataformas tecnológicas, gerando informações que contribuam para o aperfeiçoamento do planejamento estratégico e para a agilização do processo decisório.

Garantir a conectividade entre qualquer aplicação da ALESC, independente de qual plataforma ou linguagem de programação essa aplicação utilize sem a necessidade de replicação de base de dados ProcLegis

Prover meios de gestão centralizada, com acesso em tempo real às informações descentralizadas dos dados corporativos para todas as aplicações envolvidas

Assegurar a implementação de interfaces com os sistemas e soluções de gerenciamento e monitoração adotados pela ALESC, visando preservar os investimentos já realizados anteriormente e agregando valor às informações hoje existentes 
Permitir pesquisas utilizando-se de softwares especialistas de inteligência artificial;

Para controlar e preservar a transparência dos processos envolvidos a solução deve possibilitar a completa rastreabilidade das mensagens, dados e transações envolvidas no processo

Implantação de controle de fluxo de trabalho (Workflow) na ALESC

Segurança e integridade da informação

Resolução da problemática de espaço físico para armazenamento da documentação

Preservação da memória documental e conhecimento institucional

Segurança e acondicionamento adequado da documentação pública

Redução de custos, provenientes de mau gerenciamento da informação, e da má aplicação de mão-de-obra no formato atual

Melhor atendimento ao cidadão

Redução abrupta da vulnerabilidade às fraudes, nos processos a serem trabalhados; e,

Gestão integrada das informações

\subsection{Gerenciamento Eletrônico de Documentos}

Ter um sistema de Gerenciamento Eletrônico de Documentos (GED) não significa somente guardar arquivos eletrônicos e sim ter nas mãos a capacidade de gerenciar todo o capital intelectual da organização. A maioria das organizações tem uma imensa quantidade de documentos que já nascem eletrônicos: são documentos em texto, planilhas, desenhos de engenharia, e-mails. Além do acervo eletrônico, existe também o acervo em papel: projetos de lei, memorandos, cartas e outros; digitalizado através da utilização de scanners. Este novo mundo, sem gerenciamento, implica em muitas cópias de diversas versões, duplicação de arquivos, gerando a má utilização do espaço em disco e custos desnecessários de armazenamento [BALDAM e CAVALCANTI, 2002].

Para controlar esse mundo de informações digitais, quer sejam ou não originalmente eletrônicas, o conceito sobre o que é GED ampliou-se como que automaticamente. Gerenciar documentos é cuidar de toda a vida informacional da organização. GED implementa categorização de documentos, tabelas de temporalidade, ações de disposição e controla níveis de segurança, sendo vital para a manutenção das bases de informação e conhecimento.

\subsection{A Recuperação de Informações}

Objetivando viabilizar e facilitar a Gestão do Conhecimento da ALESC, serão disponibilizados softwares de Inteligência Artificial, que deverão estar integrados às soluções de Gerenciamento Eletrônico de Documentos, Gestão de fluxos de documentos e processos através do software de EAI, de forma segura e amigável.

A Recuperação de Informação com Inteligência Artificial (IA - Inteligência Artificial e IR - Information Retrieval) é uma tecnologia de normalização, indexação e recuperação de dados. Utiliza dicionários do tipo Thesaurus e mapeamento de conceitos 
na forma de Ontologias. Desta forma, atinge-se um alto grau de precisão na recuperação de informações. Árvore Hiperbólica (AH) é uma tecnologia de visualização de informação, no formato de árvore de duas dimensões, que em conjunto com a solução de Rede de Relacionamento forma uma ferramenta de visualização completa, onde o foco e o contexto podem ser observados simultaneamente [ALMEIDA e BAX, 2003].

\subsection{Segurança do ambiente}

Engloba consultorias e implantação de regras e medidas de segurança que visam diagnosticar problemas reais e potenciais de segurança do ambiente, e realizar as execuções necessárias para corrigí-los. Entre as análises e execuções previstas, estariam: análise de risco (utilizando normas ISO/ABNT 17799), política de segurança, ethical hacking (teste de penetração) externo e interno, implantações de segurança perimetral (firewalls), detecção de intrusão (IDS - Intrusion Detection System) e comissionamento dos servidores em produção (system hardening).

Para se descobrir novas vulnerabilidades e problemas de segurança, é necessário realizar a manutenção continuamente da segurança do ambiente, visando manter os níveis de segurança alcançados pela etapa anterior de consultoria e execução. Esta manutenção deve caracterizar-se por ser pró-ativa e contínua, abrangendo análise de vulnerabilidades de sistemas operacionais e serviços, gerenciamento de segurança perimetral (firewalls e roteadores), gerenciamento de detecção de intrusão (IDS) e análise de segurança dos principais servidores.

Os serviços de administração e monitoramento contínuo da segurança deverão envolver: Manutenção do firewall e IDS, ajustes da tabela de regras e de base de assinaturas; Análise de logs e de eventos de intrusão; Varreduras contínuas para busca de vulnerabilidades em servidores e estações; Análise de vulnerabilidades de aplicações Web; Ferramenta Web segura e colaborativa (com uso de certificados digitais) para acompanhamento gerencial e técnico, contendo toda a documentação dos serviços de monitoramento de segurança; Consultoria para definição, implantação e acompanhamento de política de segurança corporativa; Administrar firewall, IDS, manter/acompanhar o status de segurança de servidores e estações e desempenhar tarefas correlatas; e, finalmente, garantir o melhor atendimento ao cidadão, o acondicionamento adequado da documentação pública e a gestão integrada das informações é um dos resultados pretendidos deste projeto.

\section{Considerações Finais}

A chamada Governança Eletrônica pode ser traduzida como a capacidade financeira e administrativa de implementar políticas públicas que objetivam tornar o Estado mais forte e menor pela superação da crise fiscal, pela delimitação da sua área de atuação, distinção entre o núcleo estratégico e as unidades descentralizadas, pelo estabelecimento de uma elite política capaz de tomar as decisões necessárias e pela dotação de uma burocracia capaz e motivada.

É essencial que os canais abertos na Internet permitam à sociedade o acesso a informações de seu interesse, e que cada vez mais aplicativos sejam disponibilizados com esta finalidade. Devem-se buscar, ao mesmo tempo, aumentar a qualidade, efetividade e transparência de seus processos, atendendo aos objetivos de reorganização 
da Administração Pública, redução dos custos operacionais do processo administrativo e produção de informações para os níveis decisórios.

Em seu bojo, o projeto ora exposto visa garantir um melhor atendimento ao cidadão a partir da gestão integrada das informações na ALESC. Deste modo, a Governança Eletrônica da ALESC, que será totalmente implantada no final de 2008, será sinônimo do aumento de transparência, autonomia, capacidade financeira e administrativa para implementar políticas públicas que objetivam fortalecer o Estado de Santa Catarina.

\section{Referências Bibliográficas}

ALESC. (2006) Assembléia Legislativa do Estado de Santa Catarina. Disponível em: $<$ http://www.alesc.sc.gov.br>. Acesso em: 02 jan. 2006.

ALMEIDA, Mauricio B.; BAX, Marcello P. (2003). Uma visão geral sobre ontologias: pesquisa sobre definições, tipos, aplicações, métodos de avaliação e de construção. Ci. Inf., Brasília, v. 32, n. 3.

BALDAM, R.,VALLE, R., CAVALCANTI, M. (2002) GED: gerenciamento eletrônico de documentos. São Paulo: Érica, 204p.

BORRAS, J. (2004). International technical standards for e-government. Electronic Journal of e-Government, v. 2, n. 2, p. 75-80. ISSN: 1479-439X.

BONAVIDES, P.; ANDRADE, P. (2004) História Constitucional do Brasil. 5.ed. Editora OAB. ISBN - 85-87260-21-9.

GRAU, Nuria C. (1997) Repensando o Público Através da Sociedade, Editora Revan.

INTERSYSTEMS Corporation (2006). Avaliando Soluções de Integração - Aplicando 13 Critérios Técnicos de Seleção à Plataforma Universal de Integração Ensemble.

LAPORTE, T., DEMCHAK, C. e JONG, M. (2002). Democracy and bureaucracy in the age of the web: empirical findings and theoretical speculations. In: Administration and Society, v. 34, n. 4, September.

REZENDE, D. A; FREY, K; BERTINI R.C. (2003). Governança e Democracia Eletrônica na Gestão Urbana: Anais do Seminário Internacional em Gestão Urbana, Curitiba, PR.

RHODES, R.A.W (2000). Governance and public administration. In: Jon Pierre (ed.): Debating governance: authority, steering and democracy. New York: Oxford University Press. 